\section{Fresh gas flow and carbon dioxide rebreathing in a low pressure semi-open anaesthesia system}

We have constructed a simple system for field anaesthesia by using a Farman entrainer and a semi-open circuit to convert a draw-over apparatus to a continuous flow air $/ \mathrm{O}_{2}$ system. Compressed $\mathrm{O}_{2}$ was the driving gas for the entrainer; fresh gas (FG) delivered to the semi-open circuit was a mixture of $\mathrm{O}_{2}$, entrained air and anaesthetic vapour. The purpose of this study was to examine $\mathrm{FG}$ flow rate and $\mathrm{CO}_{2}$ rebreathing during intermittent positive pressure ventilation (IPPV). A nonrebreathing inflation valve (Laerdal) placed at the end of the expiratory (efferent) limb of the circuit vented both expiratory gas and excess FG. Ambient air IPPV was applied through the Laerdal valve from a self-inflating bag or ventilator. Since this circuit is functionally similar to a T-piece, the gas from the efferent limb $(340 \mathrm{ml}$, containing FG) entered the lungs first. If tidal volume was larger than $340 \mathrm{ml}$ the balance was ambient air. Minute ventilation of the lungs with efferent limb

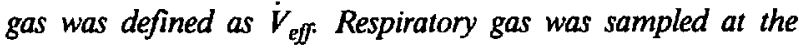
endotracheal tube and the $\mathrm{CO}_{2}$ tension was measured with a NIHON-KOHDEN $\mathrm{CO}_{2}$ analyzer. Thirty-seven adult patients having intra-abdominal or pelvic surgery under general tracheal anaesthesia were studied. Four FG flow rates $(5.7,8.0,9.3$, and $\left.10.4 \mathrm{~L} \cdot \mathrm{min}^{-1}\right)$, corresponding to driving gas pressures of 40 , 60,80 , and $100 \mathrm{~mm} \mathrm{Hg}$, were introduced in random order. Although inspired $\mathrm{CO}_{2}$ was detected at $F G$ flow rates of 5.7-9.3

\section{Key words}

ANAESTHETIC TECHNIQUES: inhalation; ANAESTHESIA COMPLICATIONS: rebreathing; EQUIPMENT: breathing systems, semi-open circuit.

From the Departments of Anaesthesia, University of Manitoba, Winnipeg, Canada, ${ }^{*}$ and Tribhuvan University Teaching Hospital, Kathmandu, Nepal. $\dagger$

Address correspondence to: Dr. W.A. Tweed, Department of Anaesthesia, Health Sciences Centre, Room LB-315, 60 Pearl Street, Winnipeg, Manitoba, Canada, R3E 1X2.

Accepted for publication 24th July, 1993.
W.A. Tweed MD FRCPC, ${ }^{*}$ R. Amatya MBBS DA, $\dagger$ B.D. Lekhak MBBS DA $†$
$L \cdot \min ^{-I}$, there were no differences in $\mathrm{PETCO}_{2}$ among the four groups. We conclude that clinically important rebreathing does not occur when $\dot{V}_{F G}$ is 1.67 times $\dot{V}_{\text {eff }}$ For general use we recommend a $\dot{V}_{F G}$ of more than twice the $\dot{V}_{e f j}$ which for this circuit configuration would be about $8 \mathrm{~L} \cdot \mathrm{min}^{-1}$. This requires a minimum $\mathrm{O}_{2}$ flow of $1.6 \mathrm{~L} \cdot \mathrm{min}^{-1}$ or driving gas pressure of $60 \mathrm{~mm} \mathrm{Hg}$.

Nous avons fabriqué un appareil de campagne pour l'anesthésie avec un entraineur Farman et un circuit semi-ouvert pour convertir un appareil à débit intermittent en débit continu air/ $\mathrm{O}_{2}$. De l'O $\mathrm{O}_{2}$ comprimé constitue la force motrice de lappareil. Le gaz frais (GF) délivré à l'appareil consiste en un mélange d'O $\mathrm{O}_{2}$, d'air entraîné et de vapeur anesthésique. L'objectif de l'étude consiste à déterminer le débit de GF et limportance $d u$ rebreathing pendant la ventilation mécanique. Une valve sans rebreathing (Laerdal) installée à l'extrémité du circuit élimine les gaz expiratoires et l'excédent de gaz frais. A la valve de Laerdal, la ventilation mécanique fonctionne à l'air ambiant mû par un ballon réservoir auto-insufflé ou un ventilateur. Le circuit fonctionne comme une pièce en $T$ et le gaz de la branche expiratoire (tube réservoir contenant $340 \mathrm{ml}$ de gaz frais) pénètre d'abord dans le poumon. Si le volume courant est plus grand que $340 \mathrm{ml}$, le reste est constitué d'air ambiant. La ventilation-minute par la branche expiratoire est appelée $\dot{V}_{e f t}$ Les gaz respiratoires sont prélevés au niveau du tube endotrachéal et la pression partielle du $\mathrm{CO}_{2}$ est mesurée par un analyseur Nihon-Kohden. Trente-sept adultes soumis à une chirurgie viscérale ou pelvienne sous anesthésie générale endotrachéale sont étudiés. Quatre débits de GF (5,7, 8,0. 9,3, et $10,4 \mathrm{~L} \cdot \mathrm{min}^{-1}$ ) correspondant à une pression motrice de 40 , 60,80 et $100 \mathrm{~mm} \mathrm{Hg}$, sont introduits de façon aléatoire. Bien qu'on puisse détecter du $\mathrm{CO}_{2}$ à des débits de $\mathrm{GF}$ de 5,7 à 9,3 $\mathrm{L} \cdot \mathrm{min}^{-1}$, on ne trouve pas de différence de $\mathrm{PETCO}_{2}$ entre les quatre groupes. Nous concluons qu'll n'existe pas de rebreathing cliniquement important avec des GF de 1,67 fois le volume courant. Pour usage général, nous recommandons un $\dot{V}_{G F}$ doubles du $\dot{V}_{\text {eff }}$ qui avec la configuration du circuit équivaut à environ $8 \mathrm{~L} \cdot \mathrm{min}^{-1}$. Ceci requiert un débit minimum $d^{\prime} \mathrm{O}_{2}$ de $1,6 \mathrm{~L} \cdot \mathrm{min}^{-1}$ ou une pression motrice de $60 \mathrm{~mm} \mathrm{Hg}$. 
In poor countries like Nepal most inhalational anaesthesia is given with draw-over systems using ambient air (often supplemented with $\mathrm{O}_{2}$ ) as the carrier gas. ${ }^{1,2}$ However, draw-over systems were not designed for the practice of modern anaesthesia and in the Western world we have come to equate modern anaesthesia with high pressure plenum systems and sophisticated anaesthesia machines. These are not affordable in underdeveloped countries, where less sophisticated delivery systems are required.

We have previously described a modification of the draw-over system for continuous flow air $/ \mathrm{O}_{2}$ anaesthesia. ${ }^{3}$ By incorporating a Farman entrainer ${ }^{4}$ and a Y-type semi-open circuit we converted the draw-over system to an economical low pressure plenum system. ${ }^{5}$ However, in the initial field trials we were not able to assess $\mathrm{CO}_{2}$ rebreathing. The purpose of this study was to examine the relationship between fresh gas flow rate $\left(\dot{\mathrm{V}}_{\mathrm{FG}}\right)$ and end-tidal $\mathrm{CO}_{2}$ during intermittent positive pressure ventilation (IPPV) using this system.

\section{Methods}

\section{Anaesthesia circuit}

The basic system shown in Figure 1 consisted of a source of compressed $\mathrm{O}_{2}$, a Farman entrainer, an Oxford Miniature Vaporizer (OMV), and an Oxford Inflating Bellows (OIB)* connected in series, and a low resistance Y-type semi-open circuit. A non-rebreathing (NR) Laerdal inflation valve placed at the end of the expiratory (efferent) limb vented expired gas and excess fresh gas (FG). By Conway's classification ${ }^{6}$ this was an efferent reservoir system. For these studies the efferent limb was a standard 32 in (82 cm) long corrugated black rubber tubing with a volume of $340 \mathrm{ml}\left(\mathrm{V}_{\text {eff }}\right)$. Positive pressure ventilation with ambient air could be provided by attaching a selfinflating bag or an air-entraining ventilator to the Laerdal inflation valve. Like a T-piece circuit, FG accumulated in the efferent limb during the expiratory phase of the ventilatory cycle. The first $340 \mathrm{ml}$ of inspiratory tidal volume $\left(\mathrm{V}_{\mathrm{T}}\right)$ was composed of efferent limb gas $\left(\mathrm{V}_{\mathrm{eff}}\right)$; the remainder was ambient air.

\section{DEFINITIONS}

$\dot{\mathrm{V}}_{\mathrm{O}_{2}}$ - Oxygen (source gas) flow rate to the Farman entrainer.

$\dot{\mathrm{V}}_{\mathrm{FG}}$ - Flow rate of fresh gas $\left(\mathrm{O}_{2}\right.$, entrained air and anaesthetic vapour) to the anaesthetic circuit.

$\dot{V}_{\text {eff }}-$ Volume of the efferent limit of the circuit.

$\dot{\mathrm{V}}_{\mathrm{eff}}$ - Minute ventilation of the lungs with efferent limb gas $\left(\dot{\mathrm{V}}_{\mathrm{eff}} \times \mathrm{RR}\right)$.

$P_{d r}-$ Entrainer driving pressure.

\section{Measuring instruments and calibration}

Respiratory gas was sampled from a T-connector attached to the endotracheal tube, the $\mathrm{CO}_{2}$ tension was measured with a Nihon-Kohden $\mathrm{CO}_{2}$ analyzer and the capnograph trace was displayed on their Life-Scope 12 monitor. $\dagger$ The $\mathrm{CO}_{2}$ analyzer was adjusted for the altitude of Kathmandu, 1300 metres, and was zeroed with room air and internally calibrated to $40 \mathrm{mmHg}$ before each study. Inspired $\mathrm{O}_{2}$ concentration $\left(\mathrm{FIO}_{2}\right)$ in the afferent limb of the circuit was measured with a Mera model OX-161 oxygen analyzer which was calibrated with room air. The pulse oximeter was a Nelcor model 200.

\section{Calibration of the Farman entrainer}

In these studies, as in Farman's original description, the source gas was $\mathrm{O}_{2}$ and the source gas pressure, that is the entrainer driving pressure $\left(\mathrm{P}_{\mathrm{dr}}\right)$, was used as a substitute measure for source gas flow rate $\left(\dot{\mathrm{V}}_{\mathrm{O}_{2}}\right)$. To establish the relationship between $\dot{\mathrm{V}}_{\mathrm{O}_{2}}$ and $\mathrm{P}_{\mathrm{dr}}$ we calibrated the entrainer in the following manner. The $\mathbf{P}_{\mathrm{dr}}$ was measured with a Tycos anaeroid manometer which had been calibrated against a mercury manometer (see Figure 1). The $\dot{\mathrm{V}}_{\mathrm{O}_{2}}$ was measured with a variable orifice rotameter type $\mathrm{O}_{2}$ flowmeter, with a freely rotating bobbin, from a Model PH-3F anaesthetic machine. $\neq$ Both back pressure and altitude will affect the height of the bobbin and therefore the flowmeter reading. We corrected for back pressure by first adjusting the flowmeter to a predetermined $P_{d n}$ then disconnecting the line to the entrainer before recording the height of the bobbin. Though the elevation of Kathmandu is 1300 metres, we did not correct the flowmeter readings for altitude. The reasons were: at low flow rates gas viscosity rather than density determines flow; we wanted the results to apply locally; and not correcting for altitude would cause a safe err by over estimating the FG flow.

Six randomized measurements were made to establish each point of correspondence and the association was tested by regression analysis (Figure 2).

Note that the relationship between $\dot{\mathrm{V}}_{\mathrm{O}_{2}}$ and $\mathrm{P}_{\mathrm{dr}}$ depends only upon the design of the entrainer, but the relationship between both and the $\dot{\mathrm{V}}_{\mathrm{FG}}$ is related to the circuit resistance distal to the entrainer. Therefore $P_{\mathrm{dr}}$ can be used as a valid surrogate measure for $\dot{\mathrm{V}}_{\mathrm{O}_{2}}$ in clinical studies.

\footnotetext{
*All these components are manufactured by Penlon Limited, Abingdon, OX14 3PH, England.

$\lceil$ Both are manufactured by Nihon-Kohden Corp., Tokyo, Japan.

‡ACOMA Anaesthetic Apparatus, Model PH-3F, 1986, supplied by ACOMA Medical Industry Co. Ltd., Tokyo, Japan.
} 


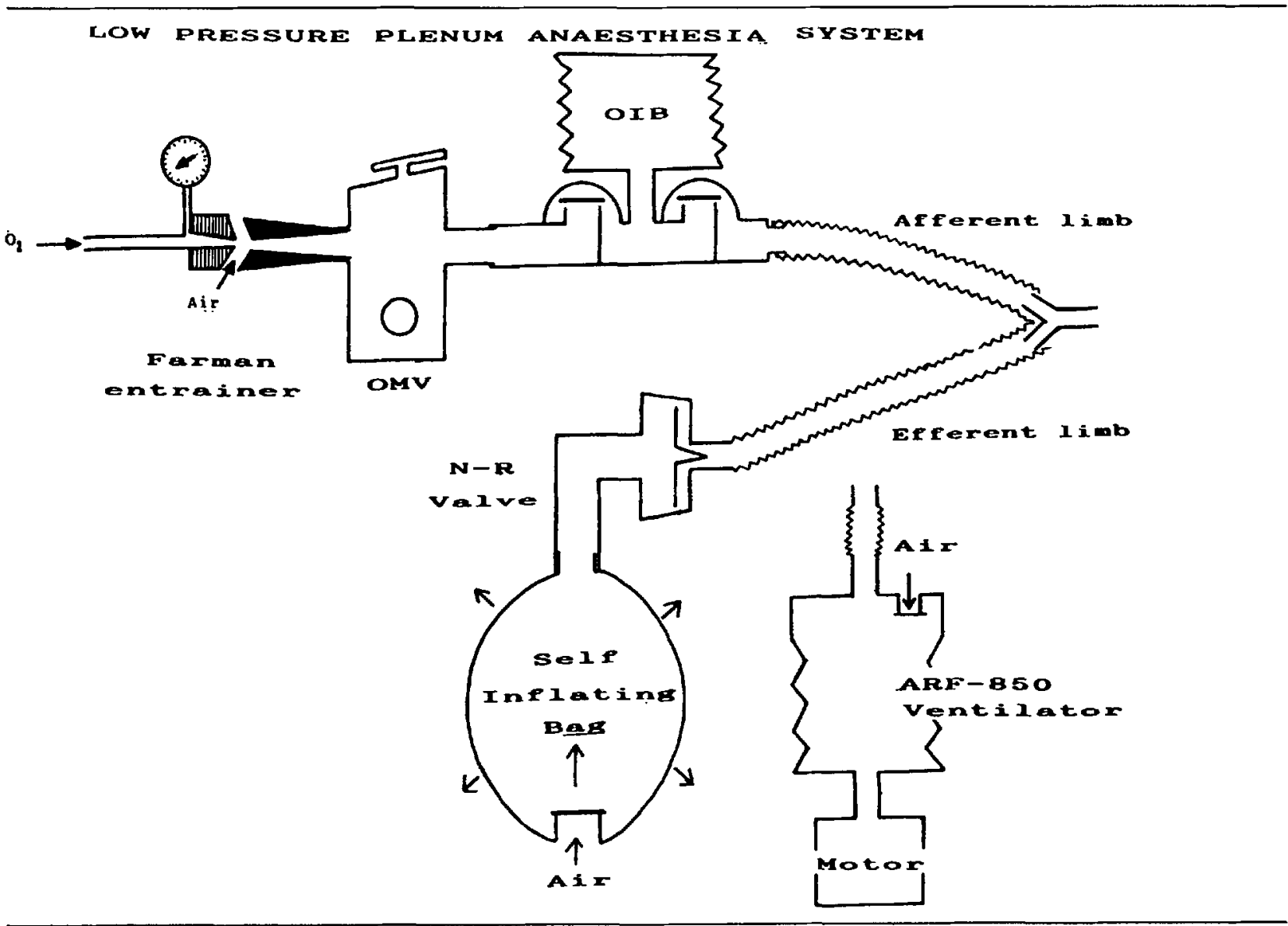

FIGURE 1 A schematic drawing of the low pressure semi-open system. OMV is the Oxford miniature vaporizer, OIB the Oxford inflating bellows, NR a Laerdal non-rebreathing inflation valve. The ARF-850 ventilator was used for intermittent positive pressure ventilation.

\section{Patient sample}

Adult ASA class I and II patients having intra-abdominal or pelvic surgery under general tracheal anaesthesia at the Tribhuvan University Teaching Hospital, Kathmandu, Nepal were selected for this study. The study was conducted in accordance with Departmental and Institutional standards for clinical investigations.

\section{Anaesthetic technique}

Anaesthesia was induced with thiopentone $4-5 \mathrm{mg} \cdot \mathrm{kg}^{-1}$ and maintained with halothane $1-2 \%$ and meperidine $0.75-1.0 \mathrm{mg} \cdot \mathrm{kg}^{-1}$. Muscle paralysis was with pancuronium and was monitored with a peripheral nerve stimulator. After tracheal intubation, ventilation of the patients' lungs was controlled by an electrically driven airentraining ARF-850 ventilator (Acoma Medical Instrument Co. Ltd., Japan). Tidal volume $\left(\mathrm{V}_{\mathrm{T}}\right)$ was set at $12-13 \mathrm{ml} \cdot \mathrm{kg}^{-1}$, respiratory rate (RR) at ten per minute and these were not changed during the study.

\section{Study design}

After the depth of anaesthesia and end-tidal $\mathrm{CO}_{2}$
$\left(\mathrm{PETCO}_{2}\right)$ had stabilized, four different FG flows $\left(\dot{\mathrm{V}}_{\mathrm{FG}}\right)$ were introduced in random order. These were set by adjusting $\dot{\mathrm{V}}_{\mathrm{O}_{2}}$ to achieve $\mathrm{P}_{\mathrm{dr}}$ of 40 (Group A), 60 (Group B), 80 (Group C) or 100 (Group D) mmHg. Steady state values for $\mathrm{PETCO}_{2}$ and $\mathrm{FIO}_{2}$ were recorded within 10-15 min after each change in $\dot{\mathrm{V}}_{\mathrm{O}_{2}}$. Rebreathing of $\mathrm{CO}_{2}$ was estimated qualitatively by examining the capnograph trace. Differences among the four groups were tested by one-way analysis of variance and for categorical data the Chi-square test was applied.

\section{Results}

Our patients were representative of the general Nepali population, that is small and lean by North American standards. Forty studies were done on 37 patients, of which 34 were female and three were studied twice. Their age was $43 \pm 11 \mathrm{yr}$ and weight was $47 \pm 9 \mathrm{~kg}$.

The relationship between $\dot{V}_{\mathrm{O}_{2}}$ and $\mathrm{P}_{\mathrm{dr}}$ at the Farman entrainer was non-linear (Figure 2), and the line of best fit was a multiplicative model of the form $\dot{\mathrm{V}}_{\mathrm{O}_{2}}=\mathrm{a}\left(\mathrm{P}_{\mathrm{dr}}\right)$, $\left(r=0.996, r^{2}=0.993\right)$. For each $P_{d r}$ the corresponding 


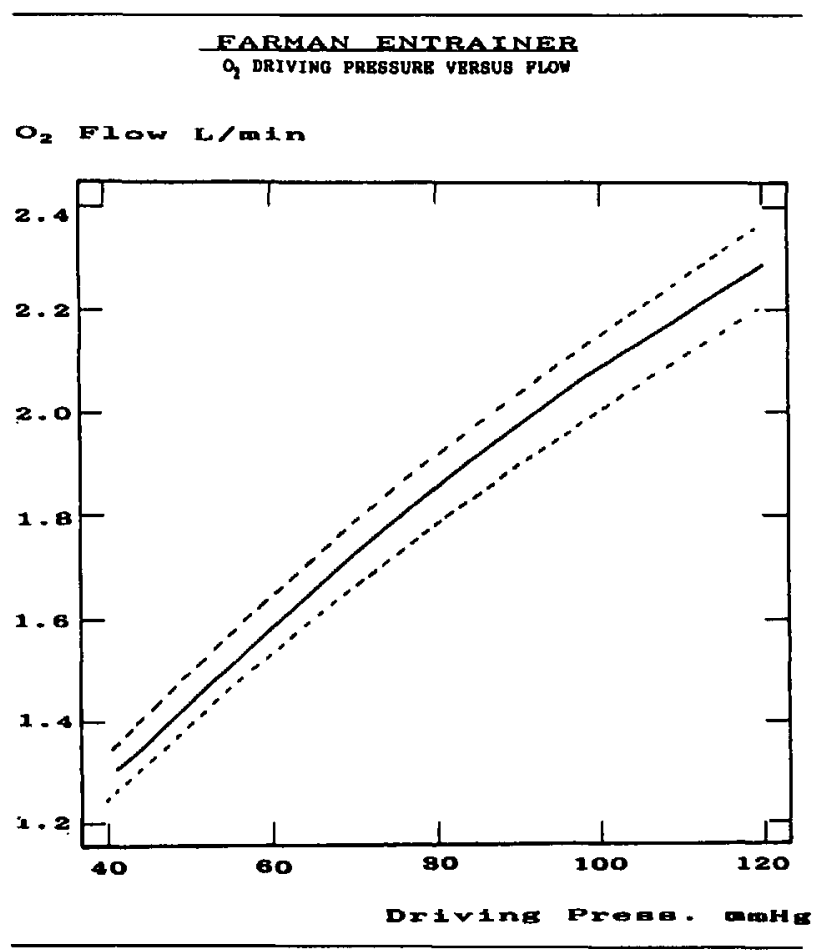

FIGURE 2 The relationship between $\mathrm{O}_{2}$ driving pressure $\left(\boldsymbol{P}_{\mathrm{dr}}\right.$ of $40-120 \mathrm{mmHg})$ and flow $\left(\dot{\mathrm{V}}_{\mathrm{O}_{2}}\right.$ of $\left.1.29-2.28 \mathrm{~L} \cdot \mathrm{min}^{-1}\right)$ at the Farman entrainer. Individual data points are not shown since all fell on or very near the line of best fit. Regression analysis identified the best fit to be a multiplicative model:

$\dot{\mathrm{V}}_{\mathrm{O}_{2}}=0.19\left(\mathrm{P}_{\mathrm{dr}}\right)^{0.52}, \mathrm{r}=0.996, P<0.0001$.

$\dot{\mathrm{V}}_{\mathrm{O}_{2}}$ was calculated from the model and is shown in row 3 of the Table.

Both experimental and derived data are presented in the Table. The mean $\mathrm{FiO}_{2}$ was 0.36 for groups $\mathrm{B}, \mathrm{C}$ and $\mathrm{D}$, that is for $\mathrm{P}_{\mathrm{dr}}$ of 60 to $100 \mathrm{mmHg}$. A constant $\mathrm{FlO}_{2}$ indicates that the air $/ \mathrm{O}_{2}$ entrainment ratio (A) was constant over this range of $P_{d r}$ The following formula relates $\mathrm{FIO}_{2}$ and $\mathrm{A}$ and can be solved for $\mathrm{A}$ :

$\mathrm{FIO}_{2}=(1+0.2 \mathrm{~A}) /(1+\mathrm{A})$,

where $A$ is the air $/ O_{2}$ entrainment ratio.

The average $\mathrm{FIO}_{2}$ of 0.36 corresponds to an entrainment ratio of 4:1 $(A=4)$. In group $D\left(P_{d r}\right.$ of $\left.40 \mathrm{mmHg}\right)$, the $\mathrm{FIO}_{2}$ was higher $(0.38, P<0.0001)$ and $\mathrm{A}$ was 3.4. Average $\dot{V}_{F G}\left(O_{2}\right.$ plus entrained air) for each group was calculated from the values for $\dot{\mathrm{V}}_{\mathrm{O}_{2}}$ and $\mathrm{A}\left[\dot{\mathrm{V}}_{\mathrm{FG}}=\dot{\mathrm{V}}_{\mathrm{O}_{2}}\right.$ $(1+\mathrm{A})]$. The range was 5.7 to $10.4 \mathrm{~L} \cdot \mathrm{min}^{-1}$.

Inspiratory $\mathrm{CO}_{2}$ was detected in $100 \%, 75 \%, 28 \%$, and $0 \%$ of studies in groups $\mathrm{A}$ to D respectively $(P<0.0001)$, but there were no differences in $\mathrm{PETCO}_{2}$ among the four groups. The statistical power of this experiment to detect a true difference in mean PETCO $\mathrm{CO}_{2}$ of $10 \%$ between any two adjacent groups was over 0.95 .
There was also no difference in $\mathrm{O}_{2}$ saturation and no saturations less than $90 \%$ were observed.

\section{Discussion}

Since the $\dot{V}_{F G}$ is a derived value based on the measurement of $\mathrm{P}_{\mathrm{dr}}$ and $\mathrm{FiO}_{2}$, the relationships between $\dot{\mathrm{V}}_{\mathrm{O}_{2}}$, $P_{d r}$ and air entrainment are central to its accurate estimation. We used a variable orifice rotameter type $\mathrm{O}_{2}$ flowmeter to measure $\dot{\mathrm{V}}_{\mathrm{O}_{2}}$. The accuracy of this type of flowmeter is stated to be between \pm 2 to $\pm 5 \%{ }^{7,8}$ Flow (F) and pressure (P) at the entrainer are related by the Bernoulli equation. For a fixed venturi the flow is predicted by the approximate formula $\mathrm{F}=\mathrm{kP}^{1 / 2}$, where $\mathrm{k}$ is a constant. ${ }^{9}$ Our data are an almost exact fit to that model and validate our use of pressure as an indicator of flow. We measured $\mathrm{FlO}_{2}$ of the downstream gas and used it to calculate the air $/ \mathrm{O}_{2}$ entrainment ratio (A) for each group. With this number and the $\dot{\mathrm{V}}_{\mathrm{O}_{2}}$ we calculated the average $\dot{\mathrm{V}}_{\mathrm{FG}}\left(\mathrm{O}_{2}\right.$ plus entrained air) for each group. Farman described the entrainer's operation only at a driving gas pressure of $100 \mathrm{mmHg}$, and reported that the consumption of driving gas was $2 \mathrm{~L} \cdot \mathrm{min}^{-1}$, the total gas flow was $10 \mathrm{~L} \cdot \min ^{-1}$, and when $\mathrm{O}_{2}$ was the driving gas the oxygen content of the final mixture was about $36 \% .^{10}$ The small difference between our estimate of $\dot{\mathrm{V}}_{\mathrm{O}_{2}}$ at $100 \mathrm{mmHg}$ and Farman's may be due to measurement error, differences in entrainers, or an effect of altitude. We are reasonably confident that our estimates are accurate to within about the error of the flowmeter, that is $\pm 5 \%$. However, since we were unable to confirm this, our recommendations for clinical use are conservative.

A constant value for $\mathrm{FIO}_{2}$ at $\mathrm{P}_{\mathrm{dr}}$ between $60-100$ $\mathrm{mmHg}\left(\dot{\mathrm{V}}_{\mathrm{O}_{2}}\right.$ of 1.59 to $\left.2.08 \mathrm{~L} \cdot \mathrm{min}^{-1}\right)$ indicates that the air $/ \mathrm{O}_{2}$ entrainment ratio (A) was constant. At a $\mathrm{P}_{\mathrm{dr}}$ of $40 \mathrm{mmHg}\left(\dot{\mathrm{V}}_{\mathrm{O}_{2}}\right.$ of $\left.1.29 \mathrm{~L} \cdot \mathrm{min}^{-1}\right)$ air entrainment decreased and $\mathrm{FIO}_{2}$ increased. At this level the pressure downstream from the entrainer is very low, probably no more than 2-3 $\mathrm{mmHg}^{6}$ and the resistance of the valves and tubing becomes a limiting factor. Therefore, we do not recommend using the entrainer at $\mathbf{P}_{\mathrm{dr}}$ of less than $60 \mathrm{mmHg}$. We did not attempt to quantitate $\mathrm{CO}_{2}$ rebreathing, but only to identify it qualitatively from the capnograph trace. Deviation of the inspiratory $\mathrm{CO}_{2}$ trace from baseline was detected at 40,60 , and $80 \mathrm{mmHg}$ entrainer pressures, but there were no differences in endtidal $\mathrm{CO}_{2}$ among the four groups. This suggests either that the amount rebreathed was clinically inconsequential, or that it occurred late in inspiration and went to the anatomical dead space. Although true differences may exist among the groups, they are likely not more than $3 \mathrm{mmHg}$, and clinically unimportant. Despite the observation that $\mathrm{CO}_{2}$ removal was adequate at an entrainer 
TABLE Experimental results. Data (mean \pm SEM)

\begin{tabular}{|c|c|c|c|c|c|}
\hline Group & $A$ & $B$ & $C$ & $D$ & \\
\hline$P_{d r} \mathrm{mmHg}$ & 40 & 60 & 80 & 100 & \\
\hline$\dot{V}_{0}, L \cdot \min ^{-1}$ & 1.29 & 1.59 & 1.85 & 2.08 & \\
\hline $\mathrm{FIO}_{2}$ & $0.38 \pm 0.00$ & $0.36 \pm 0.00$ & $0.36 \pm 0.00$ & $0.36 \pm 0.00$ & $P<.0001$ \\
\hline$\dot{\mathrm{V}}_{\mathrm{FG}} \mathrm{L} \cdot \min ^{-1}$ & 5.7 & 8.0 & 9.3 & 10.4 & \\
\hline $\mathrm{PETCO}_{2} \mathrm{mmHg}$ & $34.4 \pm 0.6$ & $33.4 \pm 0.6$ & $33.1 \pm 0.6$ & $32.6 \pm 0.5$ & NS \\
\hline Rebr. $\mathrm{CO}_{2}$ & 40 & 30 & 11 & 0 & \\
\hline No. $(\%)$ & $(100)$ & (75) & (28) & & $P<0.0001$ \\
\hline $\mathrm{O}_{2}$ Sat $\%$ & $98.4 \pm 0.3$ & $98.6 \pm 0.2$ & $98.7 \pm 0.2$ & $98.4 \pm 0.2$ & NS \\
\hline
\end{tabular}

The $\dot{\mathrm{V}}_{\mathrm{O}_{2}}$ for each $\mathrm{P}_{\mathrm{dz}}$ was determined from the best fit equation (Figure 2). Total FG flow $\left(\dot{\mathrm{V}}_{\mathrm{FG}}\right)$ equals $\dot{\mathrm{V}}_{\mathrm{O}_{2}}$ plus entrained air and was estimated from the $\dot{\mathrm{V}}_{2}$ and $\mathrm{F}_{2}$ by the following formulae:

$\mathrm{FlO}_{2}=(1+0.2 \mathrm{~A}) /(1+\mathrm{A})$

$\dot{\mathrm{V}}_{\mathrm{FG}}=\dot{\mathrm{V}}_{\mathrm{O}_{2}}(1+\mathrm{A})$

Formula ( 1 ) is solved for $A$, the air $/ \mathrm{O}_{2}$ entrainment ratio.

pressure of $40 \mathrm{mmHg}$ we do not use the entrainer at this pressure for the reason given above.

With this circuit configuration $\mathrm{CO}_{2}$ rebreathing will depend on only three factors: the volume of the efferent limb of the circuit $\left(\mathrm{V}_{\mathrm{eff}}\right)$, the $\dot{\mathrm{V}}_{\mathrm{FG}}$, and the respiratory pattern. The $V_{\text {eff }}$ should exceed the alveolar volume per breath; in these studies it was $340 \mathrm{ml}$ or an average of $7.2 \mathrm{ml} \cdot \mathrm{kg}^{-1}$ body weight. For a population of different habitus a larger size efferent tubing might be required. Since the RR was $10 \mathrm{~min}^{-1}$ minute ventilation of the lungs with gas from the efferent limb $\left(\dot{V}_{\text {eff }}\right)$ was 3.4 $\mathrm{L} \cdot \mathrm{min}^{-1}$ or $72 \mathrm{ml} \cdot \mathrm{kg}^{-1} \cdot \mathrm{min}^{-1}$. When all of the expired gas in the efferent limb was replaced by FG there would be no $\mathrm{CO}_{2}$ rebreathing and the effective ventilation of the lungs with $F G$ would be equal to $\dot{V}_{\text {eff }}$. With the usual T-piece circuit the balance would be rebreathed expired gas; with this circuit it was ambient air. To prevent clinically significant rebreathing we recommend a $\dot{V}_{\mathrm{FG}}$ of about twice the $\dot{V}_{\text {eff }}$ which requires a minimum $\mathbf{P}_{\mathrm{dr}}$ of $60 \mathrm{mmHg}$.

As with other semi-open T-piece circuits the respiratory pattern is an important determinant of $\mathrm{CO}_{2}$ rebreathing. Optimal efficiency will be achieved with a slow rate and a long expiratory pause. "I

This system has three important limitations. Should the $\mathrm{O}_{2}$ supply fail during IPPV the expiratory limb would become dead space with the risk of severe hypercapnia and hypoxaemia. Also, because of the low pressure downstream from the entrainer, stable $\dot{\mathrm{V}}_{\mathrm{FG}}$ is dependent upon low circuit resistance. Anything which might increase resistance to flow, such as sticking valves, small bore or kinked tubing, must be carefully avoided. We leave the bellows of the OIB unlocked as a visual monitor of the FG flow. A less serious limitation is the inability to vary $\mathrm{FlO}_{2}$. For those situations which require $100 \% \mathrm{O}_{2}$ we recommend that an alternative circuit, such as a Bain circuit, be kept on standby. ${ }^{12}$

In this study we have examined the operational characteristics of a low pressure continuous flow system that balance economy of operation against the risk of $\mathrm{CO}_{2}$ rebreathing. A high FG flow wastes both $\mathrm{O}_{2}$ and volatile anaesthetic. This is more serious with halothane, because of its cost, than with ether. At low driving gas pressures, less then $60 \mathrm{mmHg}$, the entrainer becomes unreliable and the risk of $\mathrm{CO}_{2}$ rebreathing increases. The entrainer operates effectively with a source gas flow rate of between 1.6-2.0 L $\cdot \mathrm{min}^{-1}$ or an entrainer driving pressure of $60-100 \mathrm{mmHg}$. This yields $\dot{\mathrm{V}}_{\mathrm{FG}}$ of 8-10 $\mathrm{L} \cdot \mathrm{min}^{-1}$, which is the range for optimal accuracy of both the OMV halothane and the EMO ether vaporizers. ${ }^{13}$

With this simple system one can practice economical, modern anaesthesia, especially where compressed gases are in short supply. It can be readily assembled from components that are available in most underdeveloped countries.

\section{References}

1 Tweed WA, Amatya R, Tuladhar TM, Maltby JR, Gurung $C K$. Anaesthesia services and the education of anaesthetists in Nepal: a model for sustainable development? Can J Anaesth 1993; 40: 993-9.

2 Ezi-Ashi TI, Papworth DP, Nunn JF. Inhalational anaesthesia in developing countries. Part 1 . The problems and a proposed solution. Anaesthesia 1983; 38: 729-35.

3 Tweed WA, Amatya $R$, Spoerel WE. Re-evaluation of the Farman entrainer in a low-pressure system for field anaesthesia. Can J Anaesth 1990; 37: 924-7.

4 Farman $J V$. Economical anaesthesia overseas: air entrainment device for use with draw-over vaporizers in children. BMJ 1965; 2: 1428. 
5 Tweed WA, Amatya R, Spoerel WE. A low-pressure portable anaesthesia system for field use: clinical trials. Can J Anaesth 1990; 37: 928-31.

6 Conway CM. Anaesthetic breathing systems. $\mathrm{Br} \mathrm{J}$ Anaesth 1985; 57: 649-57.

7 Macintosh R, Mushin WW, Epstein HG. Physics for the Anaesthetist (3rd ed). Oxford: Blackwell Scientific Publications Ltd., 1963; 202.

8 Lunn JN. The measurement of gas flow and volume. In: Scurr C and Feldman S (Eds.). Scientific Foundations of Anaesthesia. Chicago: Year Book Medical Publishers, Inc., 1974: 71-9.

9 Barker SJ, Tremper KK. Physics applied to anesthesia. In: Barash PC, Cullen BF, Stoelting RK (Eds.). Clinical Anesthesia. Philadelphia: JP Lippincot Company, 1989: 97-8.

10 Farman JV. The use of an air-entrainment device in conjunction with a draw-over vaporiser. A method for small children. Acta Anaesthesiol Scand 1966; Suppl 23: 485-90.

11 Byrick RJ, Janssen RT. Respiratory waveform and rebreathing in T-piece circuits: a comparison of enflurane and halothane waveforms. Anesthesiology 1980; 53: 371-8.

12 Lowe DM, McFadzean W. Drawover anaesthesia and preoxygenation. Br J Anaesth 1991; 66: 196-9.

13 Schaefer $H G$, Farman JV. Anaesthetic vapour concentrations in the EMO system. Anaesthesia 1984; 39: 171-80. 